\title{
The Isolation and Characterisation of Seco-phthalide Isoquinoline Alkaloid from Corydalis species
}

\author{
Ram Narayan Jha* \\ Department of Chemistry, Tri-Chandra Campus, Tribhuvan University, Kathmandu, Nepal. \\ Email: ramnarayan_jha@yahoo.co.in
}

\begin{abstract}
Chromatographic resolution of crude base fraction of the methanolic extract of the whole plant of Corydalis longipes on Silca-gel column yielded one Seco-phthalide isoquinoline alkaloid, $N$ methylhydrasteine hydroxyl lactam. Its structure was established on the basis of extensive spectroscopic data analysis and comparison with spectroscopic data reported.
\end{abstract}

Keywords: Corydalis longipes, Fumariaceae, secophthalide alkaloid.

\section{Introduction}

Corydalis longipes DC.Prodr.(Fumariaceae) a perennial herb, grows at an altitude of 2290-2350 $\mathrm{m}$ in the Himalayan region ${ }^{1,2}$. The extract of various corydalis species is reported to be efficacious in many ailments in the Indian Ayurvedic system and Chinese system of medicine ${ }^{3,4}$.There have been no medicinal use has been reported from this plant. Very few alkaloids have been isolated from Corydalis longipes; viz. adlumidine, bicuculline, cheilanthifoline, protopine, soulerine, sibirine etc. ${ }^{5,6}$. In view of the above observations, the isolation of further alkaloids from the plant Corydalis longipes has resulted in the isolation and characterization of one seco-phthalide isoquinoline alkaloid, not earlier been reported from this plant.

\section{Experimental methods}

The melting point was determined on a Toshniwal apparatus and was uncorrected. UV spectrum was recorded with Perkin-Elmer Lambde spectrophotometer using spectral methanol. An IR spectrum was recorded in $\mathrm{KBr}$ pellets. ${ }^{1} \mathrm{HNMR}$ and ${ }^{13} \mathrm{CNMR}$ spectra were recorded in $500 \mathrm{MHz}$ and $100 \mathrm{MHz}$ respectively in $\mathrm{CDCl}_{3}$ and $\mathrm{CD}_{3} \mathrm{OD}$ using tetramethylsilane as internal reference. $\mathrm{A}$ mass spectrum was recorded on Kratos M-50 mass spectrometer operating 70 Ev. The purity of the was checked on TLC plates.

The whole plants of Corydalis longipes was collected and identified by comparison with the authentic herbarium specimen. Air dried powdered whole plant of the C.longipes (1 kg) was extracted with methanol in a Soxhlet extracter which gave a brown semi solid mass $(120 \mathrm{~g})$. The methanolic extract was treated with $7 \%$ citric acid and separated to alkaloidal fraction according to the known $\operatorname{method}^{7}$.

The chloroform extract(9 g) was chromatographed over silica-gel column using solvents of increasing polarity. The elluates from $\mathrm{CHCl}_{3}: \mathrm{MeOH}$ (95:5) on crystallization from methanol yielded 41 $\mathrm{mg}$ of seco-phthalide isoquinoline alkaloid(1) identified by spectral analysis.

\section{* Corresponding author}




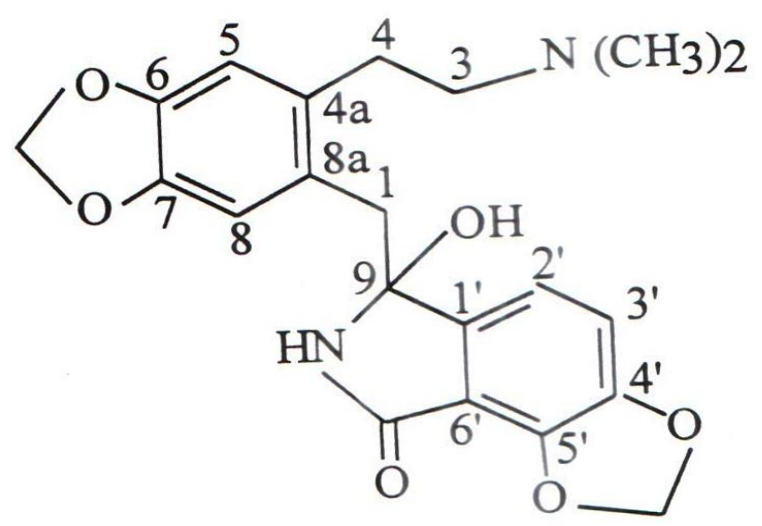

Structure: 1

\section{Seco-phthalide alkaloid}

Colourless granules, m.p.110-113 $3^{\circ}$, uv, $\lambda \max (\mathrm{MeOH}, \mathrm{nm}) ; 216,(\log \varepsilon 4.24), 293(\log \varepsilon 4.10)$ and 315 (loge 3.18); ir ( vmax, cm-1); 3320,1705, 1490, 1460, 1430,1270,; ${ }^{1} \mathrm{HNMR}\left(\mathrm{CDCl}_{3}, \delta\right) ; 1.85$ ( $\left.6 \mathrm{H}, \mathrm{S}\right)$, $2.35(2 \mathrm{H}, \mathrm{t}, \mathrm{J}=8 \mathrm{~Hz}), 2.70(2 \mathrm{H}, \mathrm{m}), 3.15(1 \mathrm{H}, \mathrm{d}, \mathrm{J}=14 \mathrm{~Hz}), 3.52(1 \mathrm{H}, \mathrm{d}, \mathrm{J}=14), 5.75(1 \mathrm{H}, \mathrm{S}), 5.80(1 \mathrm{H}, \mathrm{S}), 3.87$ $(3 \mathrm{H}, \mathrm{S}), 3.95(3 \mathrm{H}, \mathrm{S}), 6.10(1 \mathrm{H}, \mathrm{S}), 6.48(1 \mathrm{H}, \mathrm{S}), 7.15(1 \mathrm{H}, \mathrm{d}, \mathrm{J}=8 \mathrm{~Hz}), 7.35(1 \mathrm{H}, \mathrm{d}, \mathrm{J}=8 \mathrm{~Hz}), 8.0(1 \mathrm{H}, \mathrm{S})$; $100 \mathrm{Mz}^{13} \quad \mathrm{CNMR}\left(\mathrm{CDCl}_{3}, \delta\right) ; \quad 41.8(\mathrm{C}-1), 60.2(\mathrm{C}-3), 30.8(\mathrm{C}-4), 126.6(\mathrm{C}-4 \mathrm{a}), 190.4(\mathrm{C}-5), 146.4(\mathrm{C}-$ 6), 145.4(C-7),111.0(C-8),132.6(C-8a),87.0(C-9),143.0(C-1),117.4(C-2),116.4(C-3),153.4(C-4), 147.0(C$\left.5^{\prime}\right), 123.8(\mathrm{C}-6), 44.4(\mathrm{~N}-\mathrm{Me}), 44.4(\mathrm{~N}-\mathrm{Me}), 167.0(\mathrm{C}=\mathrm{O}), 100.0\left(6,7-\mathrm{O}-\mathrm{CH}_{2} \mathrm{O}\right), 56.4(4-\mathrm{OMe}), 62.6(5-\mathrm{OMe})$,; MS( m/z, relative intensity \%) 414(M+,10), $396(70), 208(25), 204(60), 58(100)$.

\section{Result and Discussion}

The seco-phthalide isoquiniline alkaloid isolated from Corydalis longipes was characterized using spectroscopic analysis. The molecular formula of compound based on the high resolution mass spectrum was found to be $\mathrm{C}_{22} \mathrm{H}_{26} \mathrm{~N}_{2} \mathrm{O}_{6} ; \mathrm{ms}, \mathrm{m} / \mathrm{z} 414.1426\left(\mathrm{M}^{+}\right), 396,208,204,58$ (base peak). The base peak at $\mathrm{m} / \mathrm{z}$ 58 suggests the fragment ion $\mathrm{CH}_{2}=\mathrm{N}^{+}(\mathrm{Me})_{2}$. Therefore, the structural unit $\mathrm{CH}_{2}=\mathrm{N}(\mathrm{Me})_{2}$ is present in compound. An intense peak at $\mathrm{m} / \mathrm{z} 396$ in the high mass region is not the $\mathrm{M}^{+}$but a fragment produced by loss of $\mathrm{H}_{2} \mathrm{O}$ either thermally or by the electron impact from the $\mathrm{M}^{+} \mathrm{m} / \mathrm{z} 414$. This is characteristic of secophthalide isoquinoline alkaloid ${ }^{8}$. The peaks at m/z 204 and 208 in the spectrum originates by rupture of bond between 1 and 9 and provided the clue to the substitution pattern in ring $\mathrm{A}$ and $\mathrm{B}$ (Mass fragmentation Fig. 1). The ultraviolet spectrum in $\mathrm{MeOH}$ showed absorption maxima at 216, 293, and $315 \mathrm{~nm}$ like that of secothalide isoquinoline alkaloids ${ }^{5}$. The infra-red spectrum in $\mathrm{KBr}$ showed $\mathrm{NH}$ group at $3220 \mathrm{~cm}-1$ and lactam at $1705 \mathrm{~cm}-1^{6}$. It also clearly indicated that the isolated alkaloid may be of secophthalide isoquinoline alkaloid having lactam group. $400 \mathrm{MHz}{ }^{1} \mathrm{HNMR}$ in $\mathrm{CDCl}_{3}$ exhibited a number of signals. The chemical shift of each signals together with there splitting pattern and probable assignment were compared with known seco-phthalide isoquinoline having lactam group ${ }^{7}$ with only difference in attachment at position C-4 and C-5, two methoxy groups are attached at $4{ }^{\top}$ and $5^{\mid}$positions whereas known seco-phthalide contain methylene dioxy group at $4^{\dagger}$ and $5^{\mid}$positions. All the other proton signals found to be similar. Hence, the structure of compound must be $\mathrm{N}$-methylhydrasteine hydroxyl lactam(1). Further the structure of compound was supported by the comparison of the ${ }^{13} \mathrm{CNMR}$ data of compound with that of reported data ${ }^{7,8}$ 


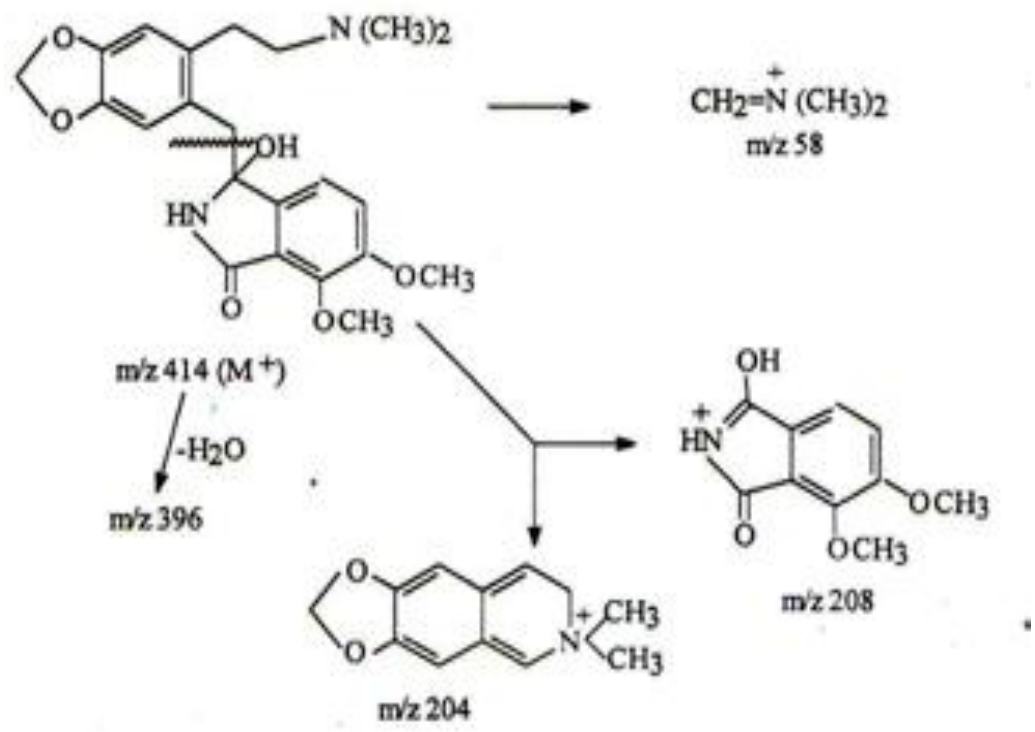

Fig. 1: Mass fragmentation pattern

\section{Conclusion}

The structure of isolated seco-phthalide isoquinoline alkaloid was determined by physical and spectroscopic method and comparison of its spectral data with those in the literature as $\mathrm{N}$ methylhydrasteine hydroxyl lactam. This is the first report of the occurrence of this alkaloid in Corydalis longipes.

\section{Acknowledgement}

Author is thankful to Prof. V. B. Pandey, Department of Medicinal Chemistry, I.M.S.,B.H.U.,Varanasi,India for spectral analysis.

\section{References}

1. Flora of Kathmandu Valley, Bulletin of the Department of Medicinal Plants, No.11,p-150,1970.

2. M. liden, Rheedea, J.Ind. Asso. For Angio. And Taxn.;1995,5,150

3. K.R.Kirtikar and B.D.Basu; Indian Medicinal Plants, L.M. Basu, Allahabad, vol.1,135, 1933.

4. W.Tang and G.Eisenbrand, Chinese Drugs of Plant Origin, Springer Verleg, New York, 377,1992 .

5. V.Preinger, The Alkaloids (Arnold Brossi), Vol.XXIX,52,1966.

6. G.Rucker, E.Breitmann, G.L.Zhang and R.Mayre; Phytochemistry,1994,36(1),579.

7. H.G.Kiryakov, Z.H.Mardirossian, D.W.Hughes, D.B. Mclean, Phytochemistry, 1986,19,2507.

8. G.Blasko, D.J.Gula and M.Shamma,; J.Nat.Prod., 1982,45,105. 